\title{
Phosphoenolpyruvate carboxykinase deficiency
}

INSERM

\section{Source}

INSERM. (1999). Orphanet: an online rare disease and orphan drug data base. Phosphoenolpyruvate carboxykinase deficiency. ORPHA:2880

Phosphoenolpyruvate carboxykinase (PEPCK) deficiency is a gluconeogenesis disorder that results from impairment in the enzyme PEPCK, and comprising cytosolic (PEPCK1) and mitochondrial (PEPCK2) forms of enzyme deficiency. Onset of symptoms is neonatal or a few months after birth and includes hypoglycemia associated with acute episodes of severe lactic acidosis, progressive neurological deterioration, severe liver failure, renal tubular acidosis and Fanconi syndrome. Patients also present progressive multisystem damage with failure to thrive, muscular weakness and hypotonia, developmental delay with seizures, spasticity, lethargy, microcephaly and cardiomyopathy. To date, there is no conclusive evidence of the existence of an isolated form of this disorder. 